\title{
Hematocrit Corrected Reticulocyte Count
}

National Cancer Institute

\section{Source}

National Cancer Institute. Hematocrit Corrected Reticulocyte Count. NCI Thesaurus. Code C102273.

The determination of the amount of hematocrit corrected reticulocytes present in a sample. 